\title{
ANALISIS DAN DESAIN SISTEM INFORMASI BIAYA PEMASARAN MARKETING PADA PT. YGI AREA SUMATERA
}

\author{
Tupan Tri M \\ Program Studi Sistem Informasi STMIK Widuri Jakarta, Indonesia \\ E-mail: tupan_tm@yahoo.com
}

Submission date : 2020-05-02

Accepted date: $2020-05-10$

\begin{abstract}
Technology that combines computer technology and telecommunications technology has changed the way of life of individuals and organizations in carrying out business activities or carrying out daily activities. The ability of communication between one organization and other organizations in different places (separated at great distances) is one of the characteristics of the coming era of globalization. The problems that exist in PT. YGI is the absence of a system that can provide marketing information to consumers. This research was conducted to gather information about marketing marketing costs, promotions, rebates, general costs and costs of branch operating funds to make decisions that are more effective, efficient, and easier for management. The author uses the method of collecting data through observation and interviews and based on theories derived from several books or journals related to the method of system design using object-oriented design methods. The results of the design and development of marketing information system marketing analysis design at PT. YGI Area Sumatra can provide solutions to problems faced in the product sales process as well as product marketing solutions for companies so that ordering products from customers increases and relationships increase. With the design of marketing information systems marketing costs can develop and publish products properly and can be seen by consumers as clearly as possible.
\end{abstract}

Keywords: Information Technology, Rebates, UMR Costs.

\begin{abstract}
ABSTRAK
Teknologi yang menggabungkan teknologi komputer dan teknologi telekomunikasi ini telah mengubah cara hidup individu maupun organisasi dalam menjalankan aktivitas bisnisnya atau menjalankan kegiatan sehari-hari. Kemampuan komunikasi antara satu organisasi dengan organisas lainnya di tempat yang berbeda (terpisah pada jarak yang jauh) merupakan salah satu ciri era globalisasi mendatang. Permasalahan yang ada pada PT. YGI ialah belum adanya suatu sistem yang dapat memberikan informasi pemasaran kepada konsumen. Penelitian ini dilakukan untuk mengumpulkan informasi mengenai biaya pemasaran marketing, promosi, rabat, biaya umr dan biaya dana operasional cabang untuk membuat keputusan yang lebih efektif, efisien, dan lebih mudah bagi manajemen. Penulis menggunakan metode pengumpulan data dengan observasi dan wawancara serta berdasarkan teori yang berasal dari beberapa buku atau jurnal terkait dan untuk metode perancangan sistem menggunakan metode desain berorientasi objek. Hasil dari perancangan dan pembangunan analisa desain sistem informasi pemasaran marketing pada PT. YGI Area Sumatera dapat memberikan solusi terhadap permasalahan yang dihadapi dalam proses penjualan produk serta sebagai solusi atas pemasaran produk bagi perusahaan sehingga pemesanan produk dari customer dapat meningkat dan bertambahnya relasi. Dengan adanya desain sistem informasi biaya pemasaran marketing dapat mengembangkan dan mempublikasikan produk dengan baik dan dapat dilihat oleh konsumen dengan sejelas mungkin.
\end{abstract}

Kata Kunci: Teknologi Informasi, Rabat, Biaya UMR

\section{PENDAHULUAN}

Kemajuan teknologi berkembang sangat cepat pada zaman modern saat ini. Inovasi dan penemuan baru selalu dilakukan setiap hari di bidang teknologi untuk mendapatkan teknologi yang canggih serta bermanfaat bagi kehidupan umat manusia.
Salah satu teknologi yang sudah terbukti mampu mendukung aktivitas-aktivitas bisnis adalah teknologi informasi. Teknologi yang menggabungkan teknologi komputer dan teknologi telekomunikasi ini telah mengubah cara hidup individu maupun organisasi dalam menjalankan aktivitas bisnisnya atau menjalankan kegiatan sehari-hari. Kemampuan komunikasi antara satu organisasi dengan organisas lainnya di tempat yang 
berbeda (terpisah pada jarak yang jauh) merupakan salah satu ciri era globalisasi mendatang (Kotler, P., \& Armstrong, 2014).

Maka sesuai dengan kebutuhan manajemen tersebut di buat program sistem informasi biaya pemasaran marketing dan penerimaan kas dengan fasilitas untuk melihat berbagai macam laporan/report yang disajikan secara menyeluruh sehingga mempermudah proses kontrol, evaluasi dan analisa data bagi pihak Marketing, Akunting. Sistem informasi didalam sebuah organisasi bertugas untuk menangkap dan mengelola data untuk menghasilkan informasi yang berguna dan efektif yang mendukung kegiatan organisasi dan seluruh level manajemen yang menggunakan, konsumen, supplier dan rekanan bisnis Sistem informasi akan membutuhkan dukungan teknologi informasi seperti mana yang biasanya sudah lazim bahwa sistem information tidak akan berarti apa-apa tanpa adanya dukungan teknologi informasi (Laudon, Kenneth C \& Laudon, 2012).

Penelitian ini bertujuan untuk mengetahui prosedur dan menganalisis sistem informasi yang sedang berjalan serta mendesain sistem informasi biaya pemasaran marketing PT. YGI Area Sumatera. Selain itu, penelitian ini juga diharapkan dapat memberikan solusi untuk meberikan bentukbentuk laporan biaya promosi, biaya UMR, biaya Rabat, biaya CN/CB yang di keluarkan kepada customer.

Sistem informasi adalah kombinasi terorganisasir yang terdiri dari orang, hardware, software, jaringan komunikasi, sumber data, dan kebijakan serta prosedur yang menyimpan, mendapatkan, merubah, dan menyalurkan informasi di dalam suatu organisasi (James A. O’Brien \& George M. Marakas, 2014).

\section{METODE PENELITIAN}

Jenis penelitian yang digunakan adalah penelitian kualitatif dengan menggunakan pendekatan action research. Penelitian ini dilakukan di bagian pemasaran PT. YGI Area Sumatera. Penelitian ini menggunakan dua sumber data, yaitu data primer dan sekunder yang diperoleh dengan menggunakan teknik pengumpulan data observasi, wawancara, dan dokumentasi. Data yang telah dikumpulkan kemudian dianalisis dengan menggunakan metode analisis data yang terdiri dari tiga tahap aktivitas yang terjadi bersama-sama yaitu data reduction, data display dan Conclusion drawing/verification (Miles, Matthew B., \& Huberman, 2014).

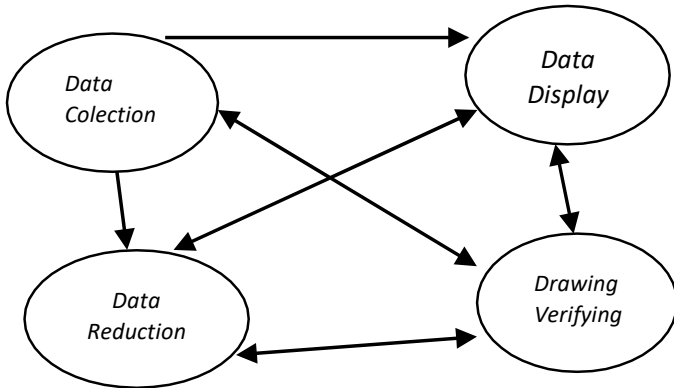

Sumber : (Tupan Tri M, 2019)

Gambar 1. Komponen Analisi Data

\section{HASIL DAN PEMBAHASAN}

\section{Analisis Kebutuhan Sistem}

Sistem informasi biaya pemasaran marketing saat ini digunakan untuk mendukung fungsi pemasaran pada PT. YGI Area Sumatera. Marketing melakukan survey terhadap pasar dalam hal ini sekolah untuk mencari informasi mengenai harga pesaing dan diskon yang berlaku di sekolah. Informasi yang di dapat nantinya akan digunakan sebagai dasar dalam menjalankan berbagai kegiatan terutama dalam membuat penawaran produk buku ke sekolah.

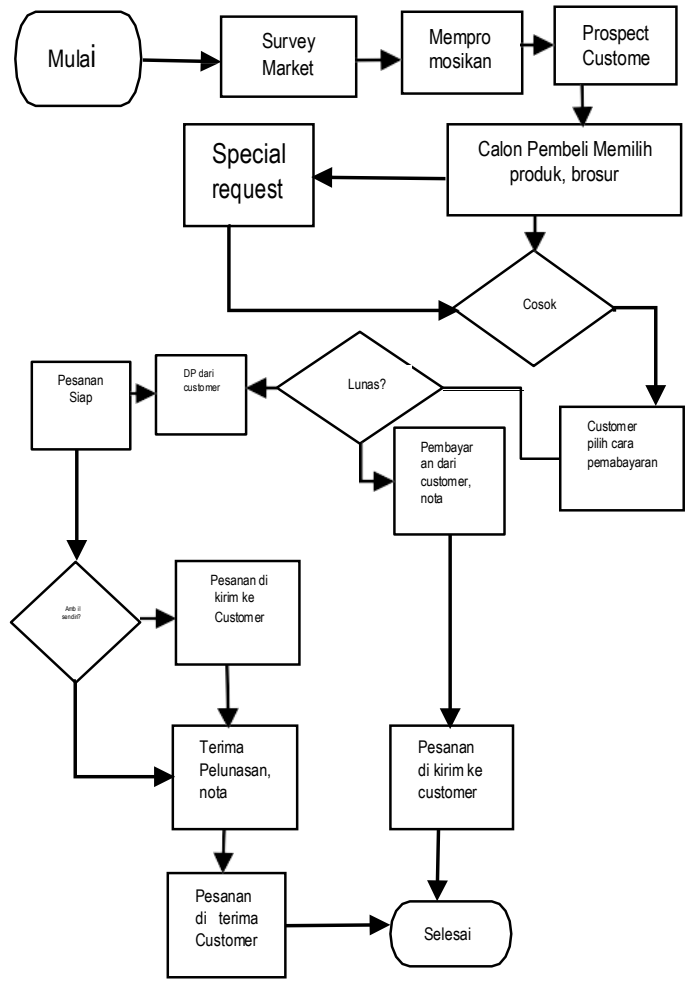

Sumber : (Tupan Tri M, 2019)

Gambar 2. Proses Bisnis Sistem Informasi Biaya Pemasaran Marketing 


\section{Desain sistem}

Desain sistem informasi biaya pemasaran marketing yang telah dianalisis sebelumnya dibuatkan ke dalam diagram konteks usulan tetap melalui interaksi 2 (dua) entitas pada gambar berikut ini (Jogiyanto HM, 2000):

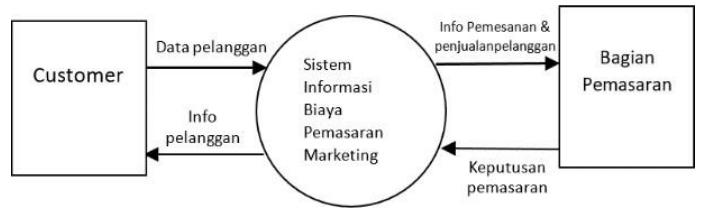

Sumber : (Tupan Tri M, 2019)

Gambar 3. Diagram Konteks Usulan

\section{Desain Halaman Utama}

Desain halaman utama pada sistem informasi biaya pemasaran marketing menyediakan fasilitas untuk melihat berbagai macam laporan/report yang disajikan secara menyeluruh sehingga mempermudah proses kontrol, evaluasi promosi, biaya dan analisa data bagi pihak Marketing. Dalam sistem informasi biaya pemsaran ini menyediakan berbagai menu laporan diantaranya : Laporan Persediaan, Laporan UMR dan Promosi, dan Laporan biaya $\mathrm{CN} / \mathrm{CB}$ Masing-masing laporan memiliki detail lanjutan, untuk melihatnya bisa dengan memanfaatkan tombol fungsi F1-F9 yang tersedia pada keyboard. Detail ini bisa dilihat pada bagian atas masingmasing report yang ditampilkan dan beberapa diantaranya meminta masukan nilai parameter sebelum menampilkan detail yang diinginkan (Agus Budiyantara , Irwansyah , Egi Prengki, Pandi Ahmad Pratama, 2020).

\section{Menu Marketing}

Menu marketing ini digunakan untuk mengetahui produktifitas salesman dan data informasi dalam menghitung komisi salesman sesuai dengan aturan komisi penjualan. Adapun menu ini terdiri dari:

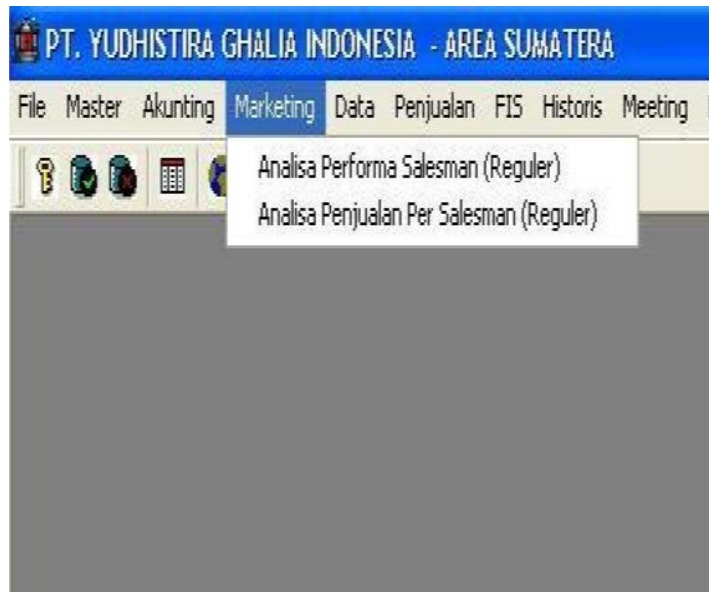

Sumber : (Tupan Tri M, 2019)

Gambar 4. Menu Marketing a) Performa Salesman (Reguler)

Masukkan Periode Ajaran misal S111 untuk Semester 1. Pilih OK Kemudian masukkan Kode Cabang.

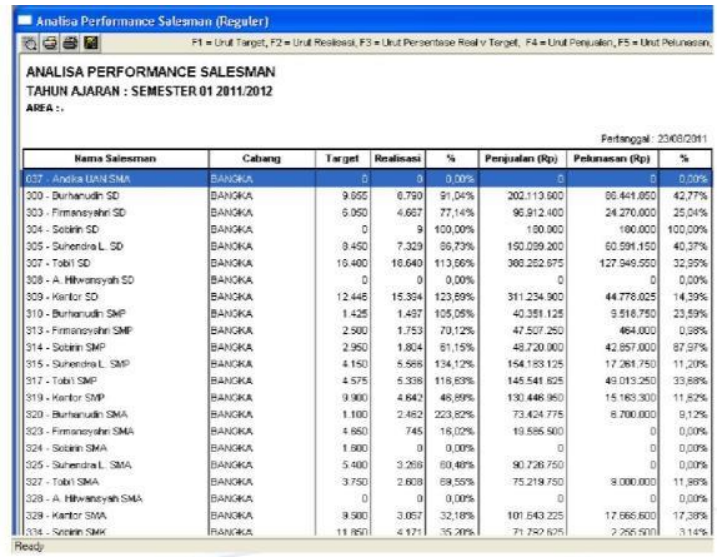

Sumber : (Tupan Tri M, 2019)

Gambar 5. Tampilan Perfoma Salesman

b) Analisa Penjualan Salesman (Reguler) Masukkan Kode Cabang dan Periode Ajaran 61issal S111 untuk Semester 1. Pilih OK Kemudian masukkan Periode UMR.

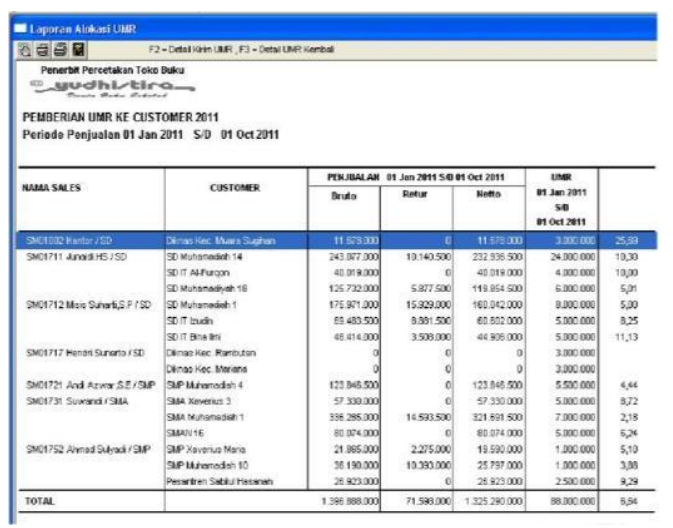

Sumber : (Tupan Tri M, 2019)

Gambar 6. Tampilan Analisa Penj Salesman

\section{Menu Data}

Menu ini merupakan kumpulan data-data yang dapat digunakan oleh bagian distribusi, dan marketing. Menu ini terdiri dari:

a) Daftar Buku \& Daftar Harga Buku

Masukkan Kode Cabang dan Kode Buku, kemudian klik tombol OK untuk menampilkan Daftar Buku dan Daftar Harga Buku dari cabang yang diinginkan.

b) Stock

Terdiri dari Stock Cabang, Stock Konsolidasi Nilai, dan Stock Mutasi Per cabang.

1. Masukkan Kode Cabang dan Kode Buku, kemudian klik tombol OK untuk menampilkan Posisi Stock Gudang. 
POSISI STOK GUDANG

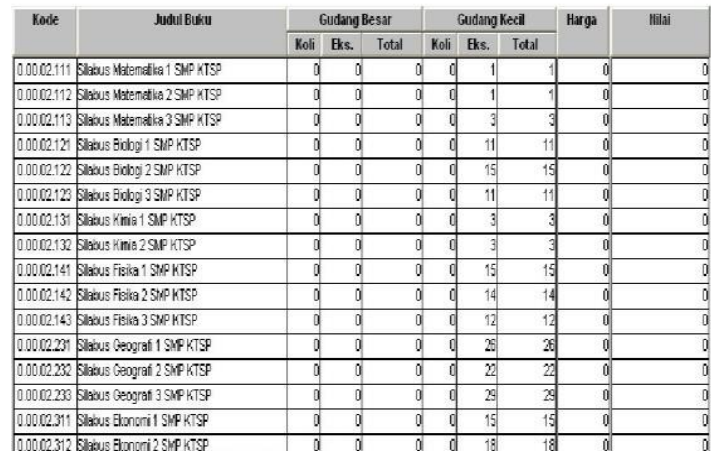

Sumber : (Tupan Tri M, 2019)

Gambar 7. Tampilan Stock

2. Masukkan Per Tanggal dan Kode Buku, kemudian klik tombol OK untuk menampilkan Stock Konsolidasi Nilai.

3. Masukkan Range Tangga dan Kode Buku, kemudian klik OK untuk menampilkan Report Mutasi Buku Konsolidasi Per Cabang.

\section{Laporan UMR}

Laporan UMR merupakan laporan yang digunakan untuk mengetahui berapa besarnya pemberian UMR ke customer/sekolah berdasarkan Surat Edaran nomor 001/04/SE/2009 tentang aturan pengelolaan UMR.

Laporan ini terdiri dari :

1. Laporan Alokasi UMR

Masukkan Kode Cabang dan Range Tanggal, kemudian klik tombol OK.

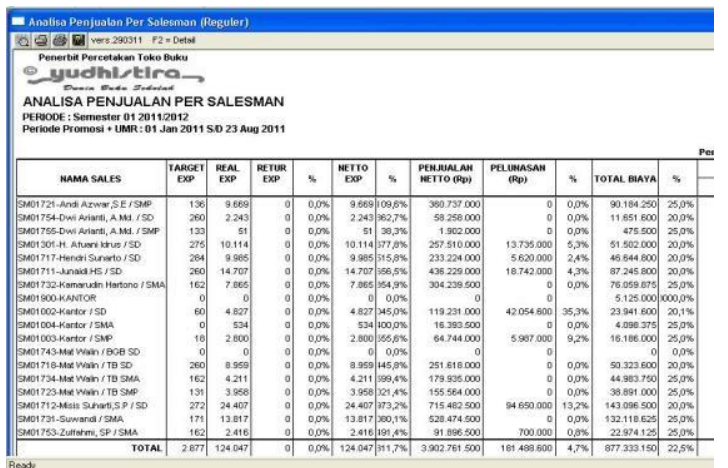

Sumber : (Tupan Tri M, 2019)

Gambar 8. Laporan UMR

2. Laporan Alokasi UMR Cabang Ke Customer Masukkan parameter Kode Cabang, Range Tanggal Periode Penjualan, dan RangeTanggal Periode UMR, kemudian klik tombol OK.

Pada Kode Cabang dan Nama Sales dipilih, tekan tombol F2 untuk menampilkan Detail Kirim UMR.

\section{Analisis}

1. Laporan ini menggambarkan tentang perbandingan antara pos-pos penjualan dengan pos-pos biaya Cabang dalam Area berdasarkan periode tahun yang dipilih. Laporan ini terdiri dari :

a. Analisa Ratio Biaya Reguler

b. Analisa Ratio Penjualan Reguler dengan Biaya Marketing ( DMC dirinci)

c. Analisa Ratio Penjualan Gabungan (faktur reguler dan non reguler) dengan Biaya Marketing ( DMC dirinci )

2. Analisa Rasio Biaya Reguler

Untuk menampilkan laporan ini, Pilih Analisa Rasio Biaya Reguler, masukkan Range Tanggal Periode Penjualan dan parameter Per Tanggal, kemudian klik tombol OK.

3. Analisa Rasio Biaya Gabungan

Untuk menampilkan laporan ini Pilih Analisa Rasio Biaya Gabungan, masukkanRange Tanggal Periode Penjualan dan parameter Per Tanggal, kemudian klik tombol OK.

4. Analisa Rasio Biaya Reguler Dengan Biaya Marketing Untuk menampilkan laporan ini Pilih Analisa Rasio Penjualan RegulerDengan Biaya Marketing, masukkan Range Tanggal Periode Penjualan dan parameter Per Tanggal, kemudian klik tombol OK.

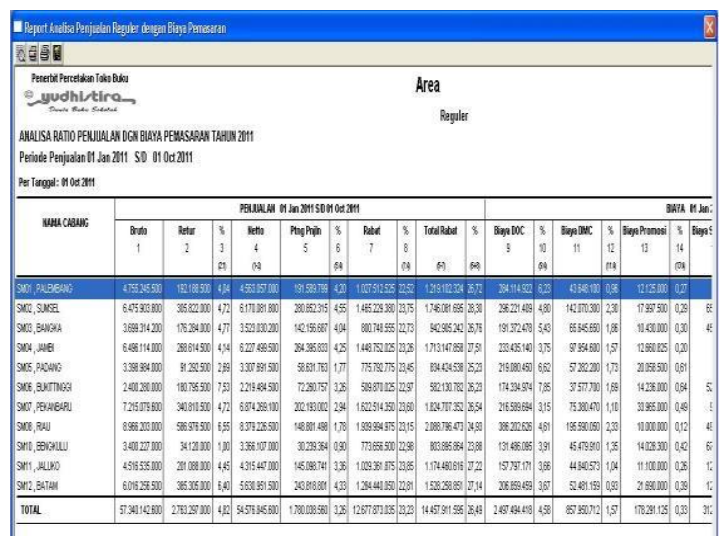

Sumber : (Tupan Tri M, 2019)

Gambar 9. Gambar Biaya Marketing

Fungsi dari semua Laporan Ratio Analisa biaya adalah :

a. Untuk mengevaluasi besarnya persentase retur yang terjadi.

b. Untuk mengevaluasi besarnya persentase potongan penjualan yang terjadi.

c. Untuk mengevaluasi besarnya persentase rabat penjualan yang terjadi.

d. Untuk mengevaluasi besarnya persentase promosi buku yang terjadi. 


\section{KESIMPULAN}

Dari berbagai penjelasan yang telah diuraikan dalam penelitian ini, maka dapat disimpulkan dengan adanya sistem ini, maka:

Perancangan dan Pembangunan analisa desain sistem informasi pemasaran marketing pada PT. YGI Area Sumatera dapat memberikan solusi terhadap permasalahan yang dihadapi dalam proses penjualan produk serta sebagai solusi pemasaran produk bagi perusahaan sehingga pemesanan produk dari customer meningkat dan bertambahnya relasi.

Dengan adanya desain sistem informasi biaya pemasaran marketing dapat mengembangkan dan mempublikasikan produk dengan baik dan dapat dilihat oleh konsumen sejelas mungkin. Dilakukannya pengujian sistem informasi biaya pemasaran marketing pada PT. YGI Area Sumatera Sistem dapat berjalan sesuai dengan yang diharapkan.

\section{DAFTAR PUSTAKA}

Agus Budiyantara , Irwansyah, Egi Prengki, Pandi Ahmad Pratama, N. W. (2020). Komparasi Algoritma Decision Tree, Naive Bayes Dan K-Nearest Neighbor Untuk Memprediksi Mahasiswa Lulus Tepat Waktu (Vol. 5, Issue 2).

James A. O’Brien \& George M. Marakas. (2014). Sistem Informasi Manajemen. Salemba Empat.

Jogiyanto HM. (2000). nalisis dan desain sistem Informasi: Pendekatan Struktur (A. Offset (ed.)).

Kotler, P., \& Armstrong, G. (2014). Principles of Marketing Global Edition (Harlow (ed.); 15th ed). England: Pearson Education.

Laudon, Kenneth C \& Laudon, J. P. (2012). Management Information Systems. Prentice Hall.

Miles, Matthew B., \& Huberman, A. M. (2014). Qualitative data analysis (A Methods Sourcebook (ed.)). Sage Publications.

Tupan Tri M. (2019). Analisis Dan Desain Sistem Informasi Biaya Pemasaran Marketing Pada PT. YGI Area Sumatera. 
